
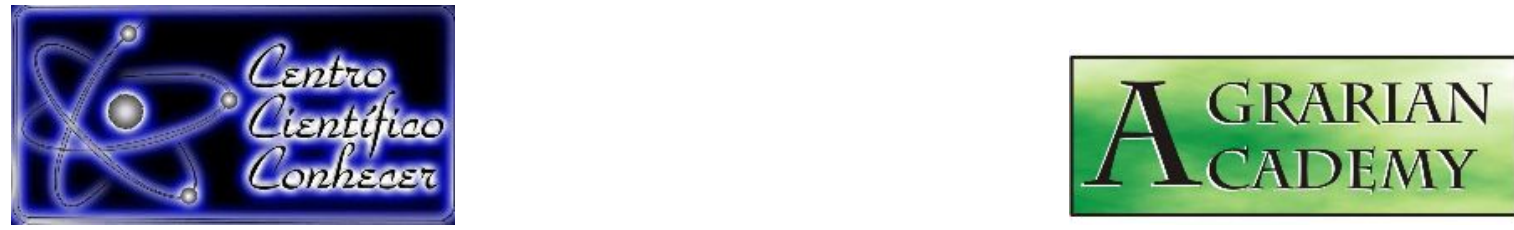

\title{
DANOS DO FOGO CAUSADOS A UM POVOAMENTO DE Eucalyptus urophylla S. T. Blake, EM IPAMERI-GO
}

\author{
Ademilson Coneglian ${ }^{1}$, Frederico Severino Barboza ${ }^{2}$, Dywre Bento da Costa ${ }^{3}$, Ismael \\ Martins Pereira ${ }^{4}$, Márcio Torreão Interamnense ${ }^{5}$ \\ ${ }^{1,4}$ Professor Doutor do Departamento de Engenharia Florestal da Universidade \\ Estadual de Goiás, Campus Ipameri, Ipameri, GO, Brasil. E-mail: coneglian@ueg.br \\ ${ }^{2,3}$ Graduando do curso de Engenharia Florestal da Universidade Estadual de Goiás, \\ Campus Ipameri, Ipameri, GO, Brasil. \\ ${ }^{5}$ Professor Mestre do Departamento de Engenharia Florestal da Universidade \\ Estadual de Goiás, Campus Ipameri, Ipameri, GO, Brasil.
}

Recebido em: 14/07/2018 - Aprovado em: 28/07/2018 - Publicado em: 31/07/2018 DOI: 10.18677/Agrarian_Academy_2018a34

\begin{abstract}
RESUMO
O objetivo desse trabalho foi investigar os danos de incêndio florestal nas características estruturais de um povoamento de Eucalyptus urophylla aos 12 anos de idade, localizado na área experimental da UEG, Campus Ipameri-GO. O Plantio consiste numa área de $0,4 \mathrm{ha}^{-1}$, onde $75 \%$ das árvores foram atingidas pelas chamas. Para avaliação da intensidade do fogo foram utilizados os parâmetros: altura de crestamento, percentagem de crestamento em relação à altura da árvore e intensidade do fogo. Para a determinação do nível de queima levou-se em consideração quatro níveis: I - Incêndio superficial sem crestamento das copas; II Incêndio superficial com crestamento parcial das copas; III - Consumo parcial das copas pela chama; IV - Consumo total das copas pela chama e/ou letalidade do câmbio. Com base na avaliação dos parâmetros estudados, a intensidade do fogo foi classificada como média, em plantio de Eucalyptus urophylla aos 12 anos de idade. Para árvores que se enquadraram ao nível de queima I, II e III, recomenda-se o monitoramento ao ataque de fungos e insetos, para não comprometer o seu incremento e a qualidade final da madeira, as plantas acometidas pelo nível de queima IV foram atingidas a temperatura de letalidade no câmbio de $60^{\circ} \mathrm{C}$, e houve incidência de brotos basais no fuste. De maneira segura, para se avaliar os danos do fogo ao câmbio, não se deve levar em consideração somente a aparência externa da casca, mais também a espessura e o tempo de permanência do fogo na área de plantio.
\end{abstract}

PALAVRAS-CHAVE: Altura de crestamento; impacto do fogo; intensidade do fogo; incêndio florestal. 


\title{
BEHAVIOR OF FIRE AND DAMAGE CAUSED TO A PEOPLEMENT OF Eucalyptus urophylla S. T. Blake, in IPAMERI-GO
}

\begin{abstract}
The objective of this work was to investigate forest fire damages on the structural characteristics of a 12-year-old Eucalyptus urophylla settlement located in the UEG
\end{abstract}

experimental area, Câmpus Ipameri-GO. The plantation consists of an area of 0.4 há

${ }^{1}$,where $75 \%$ were affected by flames. To evaluate the fire intensity, the following parameters are used: burn height, percentage of burn in relation to height and intensity the fire. For a determination of the level of burning occurred in concepts at four levels: I - surface fire without canopy burning; II - Surface fire with partial canopy burning; III - Partial consumption of the canopy by the flame; IV - Total canopy consumption by flames and / or exchange rate lethality. For trees that fit the level of burning I, II and III, it is recommended to monitor the attack of fungi and insects, in order not to compromise their increment and the final quality of the wood, the plants affected by the level of burning IV was reached the cambium. Based on the evaluation of the studied parameters, the fire intensity was classified as average in Eucalyptus urophylla of a 12 years of age. Rate lethality temperature of $60^{\circ} \mathrm{C}$, and there was incidence of basal shoots in the stem. In order to evaluate the fire damage to the exchange, one should not only consider the external appearance of the bark, but also its thickness and the time of the fire to remain in the plantation area.

KEYWORDS: burn height; fire impact; fire intensity; forest fire.

\section{INTRODUÇÃO}

Entre os principais fatores que dificultam a produção madeireira dos plantios florestais brasileiros o mais relevante é a incidência de incêndios em diferentes intensidades nos plantios, dizimando, ou inviabilizando milhares de hectares de floresta todos os anos (SOARES; TOZZINI, 1987; SOARES; 2009; CONEGLIAN et al., 2014). Tais acontecimentos se tornam cada vez mais frequentes com o aumento do material combustível nas florestas e também com o crescimento da população humana, aumentando a taxa de incêndios ocasionados por ações antrópicas (SOARES 2009; GUO et al., 2016).

Em geral os incêndios florestais têm início na serapilheira da floresta, proporcionando características peculiares há ocorrência do fogo, tornando-se umas das vertentes que possuem influência direta na ocorrência, propagação e intensidade do incêndio florestal (BEUTLING, 2009). O maior dano na vegetação após um incêndio florestal é a mortalidade das árvores e consequentemente a abertura física para infestação e proliferação de fungos, bactérias e insetos na região de sinistro (CONEGLIAN et al., 2014).

A principal causa para morte de plantas em incêndios florestais ocorre quando o câmbio vascular atinge uma temperatura letal de $60^{\circ} \mathrm{C}$, por um tempo de exposição entre um e dois minutos em regiões da base da árvore, portanto, o vegetal é exposto ao seu limite de sobrevivência, ocorrendo o perecimento de células e do câmbio, impedindo o fluxo de seiva (SOARES; BATISTA 2007; VALE; ELIAS; 2014; CONEGLIAN et al., 2014). 
Batista (2009) referencia as variáveis que podem definir o comportamento do fogo e indicar a dificuldade de extinção do incêndio, além de serem extremamente importantes para caracterizar o incêndio ocorrido. As principais variáveis são velocidade de propagação, intensidade, taxa de energia liberada, tempo de residência, temperatura máxima e altura de crestamento letal. O objetivo desse trabalho foi investigar o comportamento do fogo em plantio de Eucalyptus urophylla S. T. Blake, na área experimental da Fazenda da UEG, em Ipameri-GO.

\section{MATERIAL E MÉTODOS}

Área de estudo consiste de 0,4 hectares de Eucalyptus urophylla com 12 anos

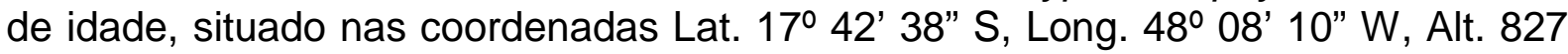
$\mathrm{m}$ localizadas na fazenda experimental pertencente à Universidade Estadual de Goiás, Campus Ipameri no município de Ipameri, GO. O tipo climático é o Aw, segundo a classificação de Köppen, caracterizado como tropical úmido com estação chuvosa no verão e seca no inverno. A temperatura média anual é de $23^{\circ} \mathrm{C}$, sendo que nos períodos de setembro a outubro pode chegar até $30^{\circ} \mathrm{C}$, entre os meses de Junho e Julho inferior a $15^{\circ} \mathrm{C}$. A precipitação média anual é $1500 \mathrm{~mm}$, concentrandose principalmente entre os meses de dezembro a março, com umidade relativa média do ar de $60 \%$ de acordo com os dados da Estação Meteorológica da Universidade Estadual de Goiás - Campus Ipameri. O solo, segundo o Sistema Brasileiro de Classificação de Solos (SANTOS et al., 2013), é Latossolo Vermelho Amarelo.

Esta área de plantio foi atingida por pelo menos dois incêndios decorrentes da prática de queima das pastagens vizinhas e/ou lixos jogados por moradores vizinhos na área durante a estação seca. O incêndio avaliado ocorreu no dia 23 de Setembro de 2017, tendo sido detectado por volta das 11:00 horas, e às 11:45 foi dado início aos trabalhos de controle com uma equipe de quatro homens. Foram utilizados abafadores, regadores, facão, foice e enxada para confecção de aceiros. O fogo foi dominado e extinto por volta das 12:35 horas do mesmo dia, evitando-se que a área total fosse queimada. $O$ incêndio atingiu por totalidade a área de $0,4 \mathrm{ha}^{-1}$ do talhão. No momento do sinistro, o plantio encontrava-se com 12 anos de idade e contendo indivíduos de até 28,5 metros de altura e cerca de $30 \mathrm{~cm}$ de diâmetro. Segundo os registros do plantio o espaçamento é de $3,00 \times 2,00 \mathrm{~m}$ tendo sido realizados dois desbastes seletivos aos seis e aos 10 anos de idade. A causa do incêndio foi identificada de origem decorrente da prática de queima das pastagens vizinhas, causado por incendiário.

\section{Variáveis climáticas no momento do incêndio florestal}

A determinação das variáveis climáticas é de fundamental importância para realizar o levantamento dos parâmetros necessários à avaliação dos danos causados pelo incêndio às árvores do plantio. De acordo com os dados meteorológicos fornecidos pela Estação Meteorológica da Universidade Estadual de Goiás, localizado no município de Ipameri-GO, no dia do sinistro o céu estava claro, a temperatura estava entre 25 e $33^{\circ} \mathrm{C}$ (observações feitas às $09 \mathrm{~h} 00 \mathrm{~min}$. e $14 \mathrm{~h} 00$ min., respectivamente; a temperatura máxima registrada foi de $33^{\circ} \mathrm{C}$, e a umidade relativa estimada estava em $9 \%$ (observações feitas no período das 13:00min. às 16:00min.). A velocidade do vento oscilou entre 5.1 e $7.2 \mathrm{~m} / \mathrm{s}$, na direção preferencial nordeste, tendo sido registrado um pico máximo de $9 \mathrm{~m} / \mathrm{s}$ na 
direção norte. A última precipitação significativa, de $17 \mathrm{~mm}$, havia sido registrada no dia 23 de Maio de 2017, portanto, 120 dias antes da ocorrência do sinistro.

\section{Determinação dos parâmetros do comportamento do fogo}

A determinação dos parâmetros do comportamento do fogo tem importância para avaliar os danos causados por incêndios florestais sobre as árvores. Os parâmetros do comportamento do fogo determinados foram: a altura da chama ou de queima, porcentagem de queima em relação à altura da árvore, intensidade do fogo, altura de crestamento e porcentagem de crestamento em relação à altura da árvore.

A altura das chamas ficou marcada nas árvores pela carbonização das suas cascas. Esta altura, que variou de acordo com a intensidade de queima, foi medida com clinômetro óptico, e através de uma regra de três simples, determinou-se a percentagem de queima em relação à altura da árvore. A intensidade do fogo foi calculada em função da altura média das chamas de cada nível de queima, através da (Equação 1) de Byram, seguindo a metodologia proposta por Coneglian et al., (2014).

$$
I=63,05 \cdot h c^{2,17}
$$

Sendo:

$I=$ Intensidade do fogo (kcal/m.s);

$h c=$ altura da chama $(\mathrm{m})$.

A estimativa da altura de crestamento letal da copa das árvores foi feita através da (Equação 2) apresentada por Coneglian et al. (2014).

Sendo:

$$
h s=\frac{3,94 \cdot I \frac{7}{6}}{\left(\left(0,107 \cdot I+V^{3}\right)^{0,5} \cdot(60-T)\right)}
$$

$h s=$ altura de crestamento letal $(\mathrm{m})$;

$V=$ velocidade do vento $(\mathrm{m} / \mathrm{s})$;

$\mathrm{l}=$ intensidade do fogo $(\mathrm{kcal} / \mathrm{m} . \mathrm{s})$;

$T=$ temperatura do ar $\left({ }^{0} \mathrm{C}\right)$.

Para a velocidade do vento e da temperatura utilizaram-se os dados referentes às $09 \mathrm{~h} 00 \mathrm{~min}$. e $14 \mathrm{~h} 00 \mathrm{~min}$., relativos ao dia do incêndio ocorrido. Através de uma regra de três simples determinou-se a percentagem de crestamento em relação à altura das árvores para cada nível de queima.

Para a determinação do nível de queima após um mês da ocorrência do incêndio, levou-se em consideração os quatro níveis descritos por Coneglian et al. (2014), verificados por intermédio da análise visual da área de queima, assim classificados e descritos. Outros aspectos abordados e analisados foram às características apresentadas pelas árvores após um mês de ocorrência do incêndio nas árvores para os níveis de queima I, II, III e IV (Figura 1).

- Nível I - Incêndio superficial sem crestamento letal das copas;

- Nível II - Incêndio superficial com crestamento parcial das copas;

- Nível III - Consumo parcial das copas pela chama;

- Nível IV - Consumo total das copas pela chama e/ou letalidade do câmbio. 

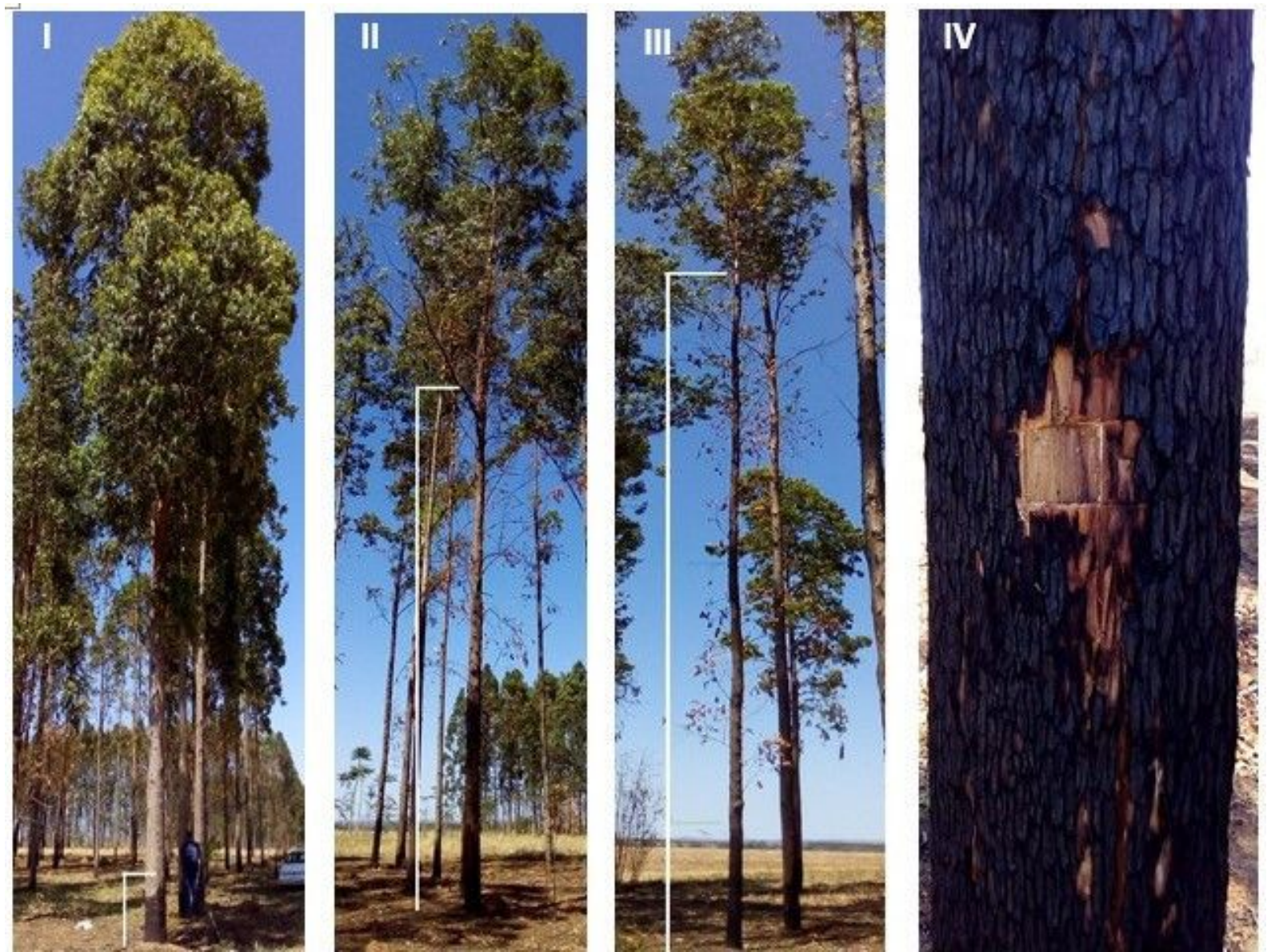

FIGURA 1. Classificação dos níveis de queima I, II, III e IV, após um mês de ocorrência do incêndio em Eucalyptus urophylla aos 12 anos de idade.

Fonte: Autores (2018)

Os níveis de queimas foram classificados por senso total das árvores danificadas pelo fogo. As medições foram realizadas em 23 de Outubro de 2017, isto é, um mês após a ocorrência do incêndio florestal. O monitoramento da sobrevivência do câmbio foi conduzido através da retirada de amostras analisadas microscopicamente, entre as regiões do súber ao câmbio.

\section{RESULTADOS E DISCUSSÃO}

\section{Comparações dos parâmetros do comportamento do fogo}

As determinações dos parâmetros do comportamento do fogo devem ser analisadas ao avaliar a taxa de sobrevivência dos indivíduos de uma população florestal. Os valores médios da velocidade do vento e da temperatura utilizados no cálculo da altura de crestamento foram $9 \mathrm{~m} / \mathrm{s}$ e $33{ }^{\circ} \mathrm{C}$, respectivamente. Considerando as variáveis climáticas verificadas no momento do incêndio, observouse que as mesmas foram favoráveis para o desenvolvimento do incêndio florestal, tendo em vista, a alta temperatura, alta velocidade do vento, baixa umidade relativa do ar, e um período de 120 dias de estiagem precedente a ocorrência. Outro fator que contribuiu para o desenvolvimento do incêndio local foi à existência de uma grande quantidade de material combustível seco, como por exemplo, grandes quantidades de resíduo florestal, folhas e galhos secos, disponíveis para queima no horizonte A do solo.

AGRARIAN ACADEMY, Centro Científico Conhecer - Goiânia, v.5, n.9; p. 3512018 
Os resultados dos parâmetros do comportamento do fogo determinados estão apresentados na Tabela 1.

TABELA 1. Comportamento dos parâmetros em diferentes níveis de queima das 109 árvores de Eucalyptus urophylla.

\begin{tabular}{ccccc}
\hline Parâmetro & $\begin{array}{c}\text { Altura de } \\
\text { Queima (m) }\end{array}$ & $\begin{array}{c}\text { Intensidade } \\
\text { do fogo } \\
\mathbf{k} \mathbf{c a l}_{\mathbf{m}} \mathbf{m}^{-1} \cdot \mathbf{s}^{-1}\end{array}$ & $\begin{array}{c}\text { Altura de } \\
\text { Crestamento } \\
(\mathbf{m})\end{array}$ & $\begin{array}{c}\text { Percentual de } \\
\text { Crestamento em } \\
\text { Relação à altura } \\
\text { das Árvores (\%) }\end{array}$ \\
\hline $\begin{array}{c}\text { Nível de } \\
\text { Queima I } \\
\text { Nível de } \\
\text { Queima II }\end{array}$ & 0,77 & 76,29 & 1,80 & 8,1 \\
$\begin{array}{c}\text { Nível de } \\
\text { Queima III }\end{array}$ & 1,92 & 127,76 & 4,52 & 20,54 \\
$\begin{array}{c}\text { Nível de } \\
\text { Queima IV }\end{array}$ & 11,38 & 423,48 & 10,27 & 46,68 \\
\hline
\end{tabular}

De acordo com tais parâmetros indicados na Tabela 1 e na Figura 2, pode se observar que o nível de queima I atingiu 34,85\% das árvores, mas não chegou a atingir a folhagem das árvores. Já para o nível II foram atingidas $40,36 \%$ das árvores do plantio e houve apenas um crestamento parcial das copas. A altura média das chamas no nível de queima II atingiu aproximadamente $20,54 \%$ da altura total das árvores e a intensidade média do fogo foi de $127,76 \mathrm{kcal} \cdot \mathrm{m}^{-1} \cdot \mathrm{s}^{-1}$.

As intensidades observadas não excederam o limite de $132 \mathrm{kcal} . \mathrm{m}^{-1} . \mathrm{s}^{-1}$ que, segundo Brown e Davis (1973), seria um limite máximo que um povoamento florestal poderia suportar sem sofrer danos. Os valores de intensidade do fogo Eucalyptus urophylla aos 12 anos de idade foram classificado como médios, de acordo com a escala de McArthur e Cheney (1966), superiores aos apresentados por Coneglian et al. (2014) em Acácia mangium aos três anos de idade, cujas medições variaram entre 40 e $>132 \mathrm{kcal} . \mathrm{m}^{-1}$. $\mathrm{s}^{-1}$ para os níveis queima II e III, respectivamente. Contudo Camagos et al. (2015) avaliaram os parâmetros do comportamento do fogo e encontraram valores de 11,94 a $75,79 \mathrm{kcal} \cdot \mathrm{m}^{-1} \cdot \mathrm{s}^{-1}$, sendo classificado em muito baixo para um trecho de Floresta Estacional Semidecídua.

Com relação ao nível de queima III esta atingiu 12,82\% das plantas e o fogo chegou a queimar até cerca de $46,68 \%$ da altura média, tendo uma intensidade média alcançada pelo fogo de $423,48 \mathrm{kcal} . \mathrm{m}^{-1} . \mathrm{s}^{-1}$ apresentando grandes chances de sobrevivência. Os valores apresentados estão em conformidade com os dados expostos por Soares e Batista (2007), nos quais apontam que a intensidade de um incêndio florestal, pode chegar a variar de 400 a $800 \mathrm{Kcal} / \mathrm{s}^{-1} \mathrm{~m}^{-1}$ e acima destes valores, geralmente, o fogo torna-se incontrolável. 


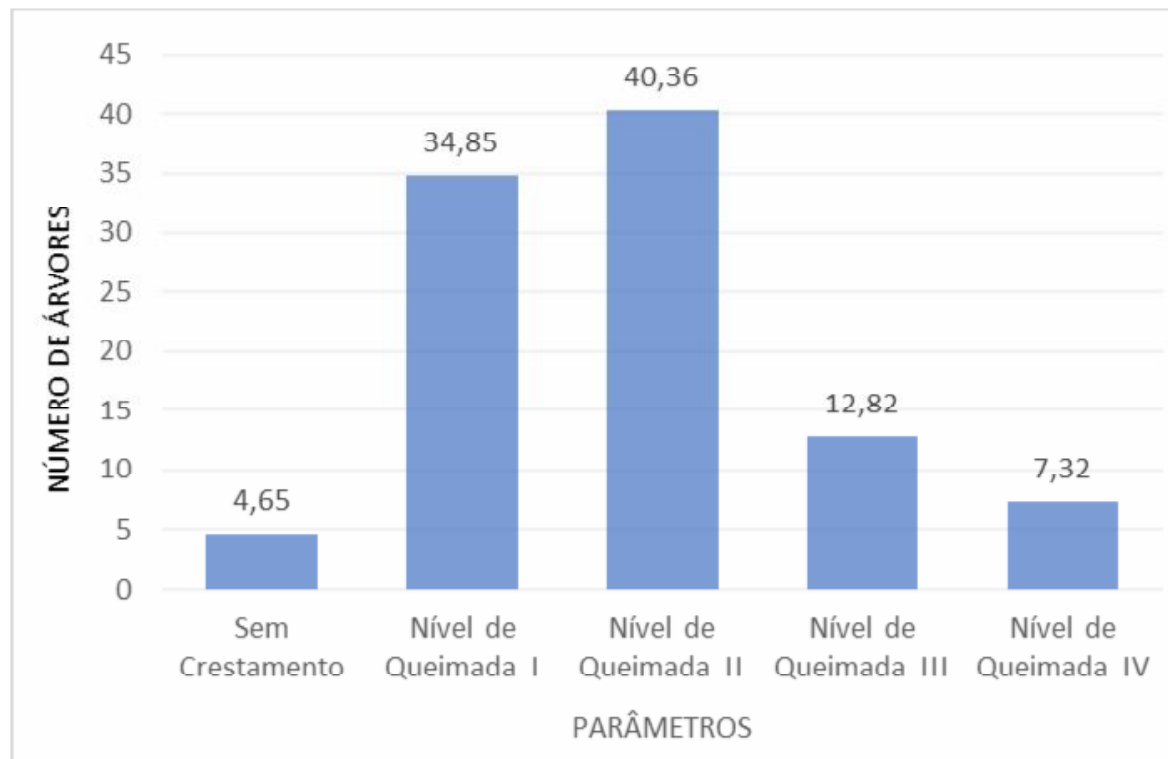

Figura 2. Distribuição das árvores para cada nível de queima segundo a classificação de Byram.

Fonte: Autores (2018)

Ao todo oito árvores $(7,32 \%)$ atingiram o nível de queima IV, sendo expostas a temperatura letal de $60^{\circ} \mathrm{C}$ ou superiores com um tempo de exposição entre um e dois minutos o que causou a mortalidade do cambio. A média de espessura da casca apresentada na Figura 3 foi de $6,2 \mathrm{~mm}$, esses dados corroboram com a afirmação de Byram (1958) e Uhl e Kauffman (1990) em que a temperatura letal ao câmbio ocorre a $60^{\circ} \mathrm{C}$, para todas as árvores com espessura de casca igual ou inferior a $6,4 \mathrm{~mm}$, com o tempo de exposição ao fogo intenso, de um a cinco minutos.

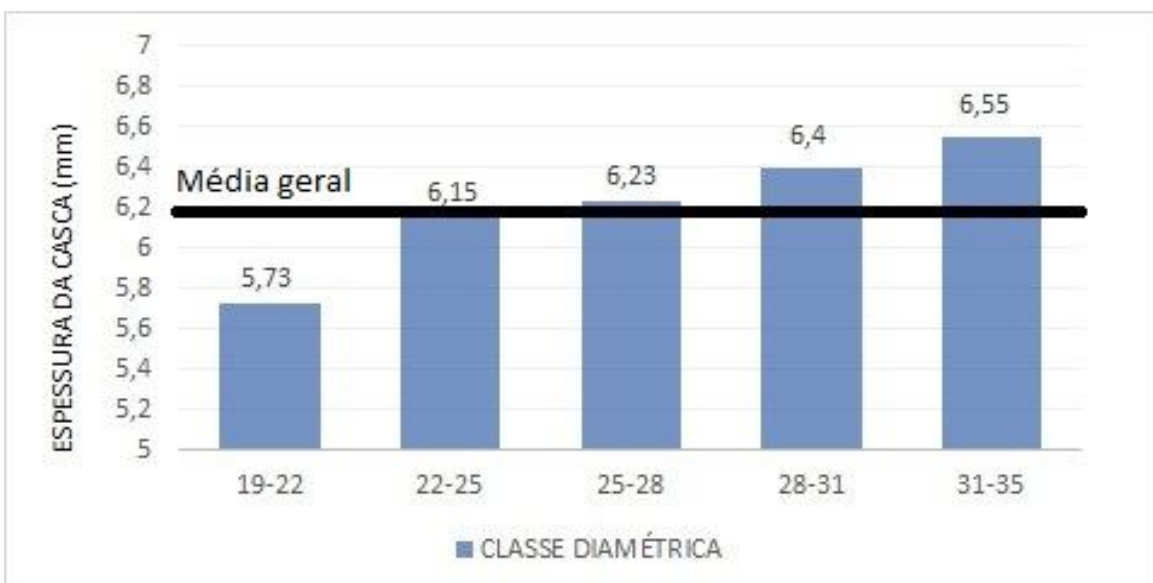

Figura 3. Médias de espessura de casca segundo cada classe diamétrica, e média geral da espessura da casca.

Fonte: Autores (2018)

Em todas as árvores atingidas pelo nível IV de queima foi observada: a perda de copa e o surgimento de brotos na região basal, isso ocorreu devido a mortalidade do cambio ao longo do fuste (Figura 4). Essas informações estão em consonância AGRARIAN ACADEMY, Centro Científico Conhecer - Goiânia, v.5, n.9; p. 3532018 
com os dados de Moctezuma et al. (2015), que estudaram a tolerância ao fogo de Quercus magnoliifolia e de conformidade com Rodríguez t. e Myers (2010), em que a brotação na base do fuste é uma adaptação devido a inatividade do cambio e perda de copa devido ao incêndio florestal.

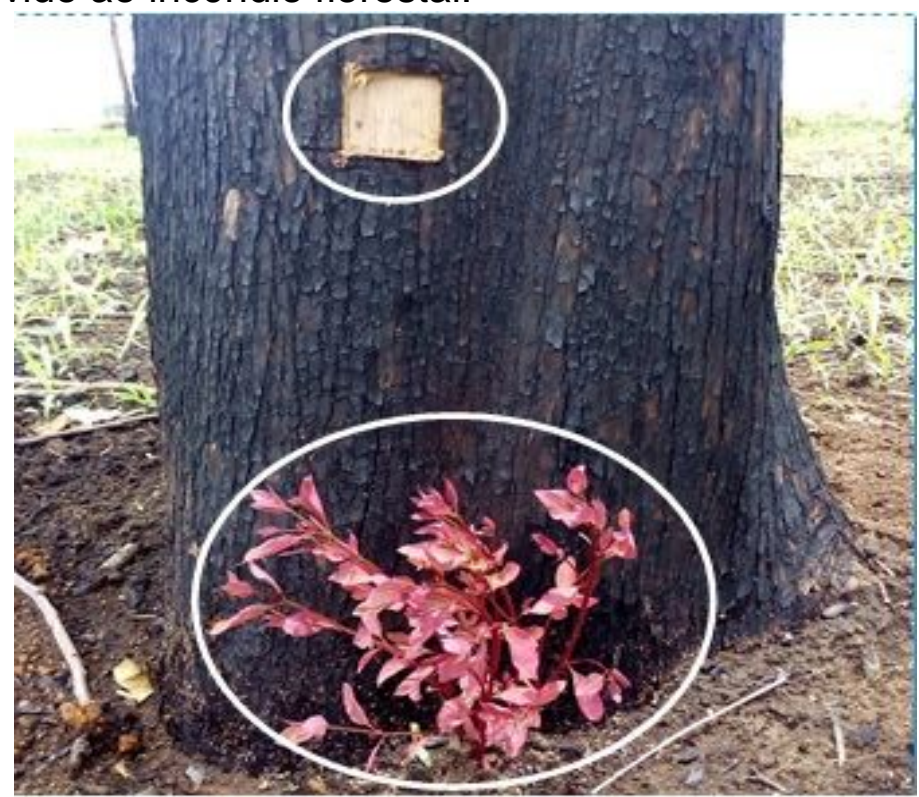

Figura 4. Rebrota basal de planta de Eucalyptus urophylla após perda da copa por mortalidade do câmbio.

Fonte: Autores (2018)

A média de espessura de casca do Eucalyptus urophylla aos 12 anos de idade foi de $6,2 \mathrm{~mm}$, o que proporcionou ao câmbio uma segurança, essas informações estão em consonância com Gava et al. (1995), que mencionam que após atingida a temperatura letal, a casca se mantém por maior tempo, em termos absolutos, o teor de água é superior, favorecendo que uma maior quantidade de calor seja armazenada e que, consequentemente, eleva o tempo necessário para liberá-lo, reduzindo as chances de sobrevivências, o que é confirmado pelos estudos de Hachmi et al. (2011) e Batista e Biondi (2009) que constataram que o teor de umidade da casca está intimamente relacionado com a propagação do fogo. A metodologia apresentada para estimativa dos parâmetros do comportamento do fogo mostrou-se adequada para avaliação dos danos causados após um mês do incêndio florestal no povoamento de E. urophylla.

\section{CONCLUSÃO}

Com base na avaliação dos parâmetros estudados, a intensidade do fogo foi classificada como média, em plantio de Eucalyptus urophylla aos 12 anos de idade.

Para árvores que se enquadraram ao nível de queima I, II e III, recomenda-se o monitoramento ao ataque de fungos e insetos, para não comprometer o seu incremento e a qualidade final da madeira. O nível de queima IV atingiu a temperatura de letalidade no câmbio de $60^{\circ} \mathrm{C}$ em oito árvores, com incidência de brotos basais no fuste.

De maneira segura, para se avaliar os danos do fogo ao câmbio, não se deve levar em consideração somente a aparência externa da casca, mais também sua espessura e o tempo de permanência do fogo na área de plantio. 


\section{AGRADECIMENTOS}

Agradecemos à Universidade Estadual de Goiás, Campus Ipameri, pela autorização da realização deste trabalho e ao NEAP (Núcleo de Estudos Avançados em Plantas Agrícolas e Florestais) pelo apoio e logística.

\section{REFERÊNCIAS}

BATISTA, A. C.; BIONDI, D. Avaliação da inflamabilidade de Ligustrum licidum Aiton (Oleaceae) para uso potencial em cortinas de segurança na região sul do Brasil. Revista Brasileira de Ciências Agrárias, v. 4, n. 4, p. 435,439, 2009. Disponível em: $<$ http://www.agraria.pro.br/ojs2.4.6/index.php?journal=agraria\&page $=$ article \&op $=$ view $\&$ path $\% 5 \mathrm{~B} \% 5 \mathrm{D}=105 \&$ path $\%$ $5 \mathrm{~B} \% 5 \mathrm{D}=199>$ doi: 10.5039/agraria.v4i4a11

BATISTA, A. C. Estudos sobre o comportamento do fogo na Universidade Federal do Paraná. In SOARES, R. V.; BATISTA, A. C.; NUNES, J. R. S. Incêndios florestais no Brasil: o estado da arte. Gráfica Capital, 2009. p. 35-52. ISBN - 97885-904353-4-1

BEUTLING, A. Combustíveis florestais. In: SOARES, R. V.; BATISTA, A. C.; NUNES, J. R. S. Incêndios florestais no Brasil: o estado da arte. Gráfica Capital, 2009. p. 21-34. ISBN - 978-85-904353-4-1

BROWN, A.A.; DAVIS, K.P. Forest fire: control and use. 2nd ed. New York. McGraw-Hill Book Company, 1973. 686 p. ISBN - 9780070082052 \& 0070082057

BYRAM, G. M. Some basic thermal processes controlling the effects of fire on living vegetation. USDA Forest Service Southeast Forest Experiment Station, Res. Note, Asheville n.114, 1958. 2 p.

CAMARGOS, V. L.; RIBEIRO, G. A.; SILVA, A. F.; MARTINS, S. V.; CARMO, F. M. S. Estudo do comportamento do fogo em um trecho de floresta estacional semidecídua no município de viçosa, Minas Gerais . Revista Ciência Florestal [online]. 2015, v.25, n.3, pp.537-545. ISSN 0103-9954. Disponível em: http://www.scielo.br/pdf/cflo/v25n3/1980-5098-cflo-25-03-00537.pdf http://dx.doi.org/10.5902/1980509819605.

CONEGLIAN, A.; BIAZINI, L. D. P.; BARROS, S. M. B. de; PEREIRA, I. M. Avaliação de danos causados por incêndio florestal em plantios de Acacia mangium Willd., utilizados como processo de estabilização de voçoroca. Revista Científica de Engenharia Florestal, v. 23, n. 1, p. 1-10, 2014. Disponível em:

$<$ http://faef.revista.inf.br/imagens_arquivos/arquivos_destaque/gpzBHnyjKsJDdyN_2 014-6-13-13-43-9.pdf>

GAVA, J. L.; OMETTO, M. L.; NIBE, T. M. M.; SEIXAS F. Influência da espessura da casca de Eucalytpus torelliana e Eucalyptus tereticornis sobre a variação da temperatura do câmbio durante a ocorrência de um incêndio florestal. Instituto de 
Pesquisas e Estudos Florestais, n. 48/49, p. 126-132, 1995. Disponível em: <http://www.ipef.br/publicacoes/scientia/nr48-49/cap13.pdf>

GUO, F.; ZHANG, L.; JIN, S.; TIGABU, M.; SU, Z. WANG, W. Modeling anthropogenic fire occurrence in the Boreal Forest of China using logistic regression and random forests. Forests, v. 7, n. 11, p. 250-264, 2016. Disponível em: <http://www.mdpi.com/1999-4907/7/11/250/htm\#B4-forests-07-00250> doi: http://dx.doi.org/10.3390/f71102501

HACHMI, M.; SESBOU, A.; BENJELLOUN, H.; EL HANDOUZ, N.; BOUANANE, F. A Simple technique to estimate the flammability index of Moroccan forest fuels. Journal of Combustion, v. p. 1-11, 2011. Disponível em: <https://www.hindawi.com/journals/jc/2011/263531/> doi: http://dx.doi.org/10.1155/2011/263531

Mc ARTHUR, A. G.; CHENEY, N.P. The characterization of fire in relation to ecological studies. Australian Forest Research, Australian, v. 2, n. 3, p. 36-45, 1966.

https://fireecologyjournal.org/docs/Journal/pdf/Volume11/lssue01/001.pdf

MOCTEZUMA, M. Á. L.; TREJO, D. A. R; CORTÉS, F. S.; ChÁVEZ, V. A. S.; SÁNCHEZ, D. G. TOLERANCIA AL FUEGO EN Quercus magnoliifolia. Revista Árvore, v. 39, n. 3 p. 523-533, 2015, Disponível: <http://www.scielo.br/pdf/rarv/v39n3/0100-6762-rarv-39-03-0523.pdf> doi: http://dx.doi.org/10.1590/0100-67622015000300013

RODRÍGUEZ, T., D.A.; MYERS, R.L. Using oak characteristics to guide fire regime restoration in Mexican pine-oak and oak forests. Ecological Restoration, v.28, n.3, p.304-323, 2010. Disponível em:< http://er.uwpress.org/content/28/3/304.abstract> doi: http://dx.doi.org/10.3368/er.28.3.304

SANTOS, H. G. dos; JACOMINE, P. K.; T.; ANJOS, L. H. C. dos; OlIVEIRA, V. Á. de; LUMBRERAS, J. F.; COELHO, M. R.; ALMEIDA, J. A. de; CUNHA, T. J. F.; OLIVEIRA, J. B. de. Sistema Brasileiro de Classificação de Solos, 2013, 3.ed. Embrapa Solos, Brasília. 353 p. ISBN 978-85-7035-198-2

SOARES, R. V.; TOZZINI, D. S. Relações entre o comportamento do fogo e danos causados a um povoamento de Pinus taeda. Revista Floresta, v. 17, n.2, p.9-13, 1987. Disponível em: < http://revistas.ufpr.br/floresta/article/view/6377/4574 > doi: http://dx.doi.org/10.5380/rf.v17i12.6377

SOARES, R. V. Estatística dos incêndios florestais no Brasil. In: SOARES, R. V.; BATISTA, A. C.; NUNES, J. R. S. Incêndios florestais no Brasil: o estado da arte. Gráfica Capital, 2009. p. 1-20. ISBN - 978-85-904353-4-1

SOARES, R. V.; BATISTA, A. C. Incêndios florestais: controle, efeitos e uso do fogo. 2007. 264 p. Bibliografia: p. 224-238. ISBN - 978-85-904353-2-7 
UHL, C.; KAUFFMAN, J. B. Deforestation, fire susceptibility, and potential tree responses to fire in the earstern Amazon. Ecology, v. 71, n. 2, p. 437- 499, 1990. Disponível em: <https://esajournals.onlinelibrary.wiley.com/doi/abs/10.2307/1940299> doi: https://doi.org/10.2307/1940299

VALE, A. T.; ELIAS, P. S. Nível de proteção térmica da casca de quatro espécies lenhosas e a relação da arquitetura da casca com a transferência de calor. Ciência Florestal, Santa Maria, v. 24, n. 4, p. 979-987, 2014. Disponível em: < http://www.scielo.br/scielo.php?pid=S1980$50982014000400979 \&$ script=sci_abstract\&tlng=pt> doi: http://dx.doi.org/10.1590/1980-509820142404017 